NBER WORKING PAPER SERIES

\title{
ON THE ORIGINS OF DISHONESTY: FROM PARENTS TO CHILDREN
}

\author{
Daniel Houser \\ John A. List \\ Marco Piovesan \\ Anya Savikhin Samek \\ Joachim Winter \\ Working Paper 20897 \\ http://www.nber.org/papers/w20897
}

\author{
NATIONAL BUREAU OF ECONOMIC RESEARCH \\ 1050 Massachusetts Avenue \\ Cambridge, MA 02138 \\ January 2015
}

We thank the Becker Friedman Institute staff and our 2011 summer interns for help in conducting experiments, especially Jennie (Jai) Huang. We thank Lydia Zepeda for valuable input. This research is based on work supported by the Kenneth and Anne Griffin Foundation and the John Templeton Foundation. Any opinions, findings, and conclusions expressed in this paper are the views of the authors and do not reflect the views of the funding agencies. The views expressed herein are those of the authors and do not necessarily reflect the views of the National Bureau of Economic Research.

NBER working papers are circulated for discussion and comment purposes. They have not been peerreviewed or been subject to the review by the NBER Board of Directors that accompanies official NBER publications.

(C) 2015 by Daniel Houser, John A. List, Marco Piovesan, Anya Savikhin Samek, and Joachim Winter. All rights reserved. Short sections of text, not to exceed two paragraphs, may be quoted without explicit permission provided that full credit, including $\odot$ notice, is given to the source. 
On the Origins of Dishonesty: From Parents to Children

Daniel Houser, John A. List, Marco Piovesan, Anya Savikhin Samek, and Joachim Winter

NBER Working Paper No. 20897

January 2015

JEL No. C9,C91,C93

\begin{abstract}
$\underline{\text { ABSTRACT }}$
Acts of dishonesty permeate life. Understanding their origins, and what mechanisms help to attenuate such acts is an underexplored area of research. This study takes an economics approach to explore the propensity of individuals to act dishonestly across different economic environments. We begin by developing a simple model that highlights the channels through which one can increase or decrease dishonest acts. We lend empirical insights into this model by using an experiment that includes both parents and their young children as subjects. We find that the highest level of dishonesty occurs in settings where the parent acts alone and the dishonest act benefits the child rather than the parent. In this spirit, there is also an interesting effect of children on parents' behavior: in the child's presence, parents act more honestly, but there are gender differences. Parents act more dishonestly in front of sons than daughters. This finding has the potential of shedding light on the origins of the widely documented gender differences in cheating behavior observed among adults.
\end{abstract}

Daniel Houser

George Mason University

4400 University Drive, MSN 1B2

Fairfax, VA, 22030

dhouser@gmu.edu

John A. List

Department of Economics

University of Chicago

1126 East 59th

Chicago, IL 60637

and NBER

jlist@uchicago.edu

Marco Piovesan

Department of Economics

University of Copenhagen

Øster Farimagsgade 5

DK-1353 Copenhagen K

Denmark

Marco.Piovesan@econ.ku.dk
Anya Savikhin Samek

University of Wisconsin, Madison

1300 Linden Drive

Madison, WI 53706

anyasamek@gmail.com

Joachim Winter

Department of Economics

LMU Munich

Ludwigstr. 33

D-80539 Munich

Germany

winter@lmu.de 


\section{Introduction}

Individuals encounter opportunities to act dishonestly for personal gain in all areas of life. People cheat on taxes, over-charge clients, steal from the workplace, download music and movies from the Internet illegally, and use public transportation without paying the fare. Such 'small scale but mass cheating' (Ariely, 2012) acts have great social and economic costs. ${ }^{1}$ In addition to the direct pecuniary cost to business and government, the prevalence of dishonesty has detrimental impacts on the inner-workings of modern economies. As expressed by Arrow over three decades ago, "Virtually every commercial transaction has within itself an element of trust ... It can be plausibly argued that much of the economic backwardness of the world can be explained by a lack of mutual confidence."

While economists have made important strides to explore the prevalence and importance of dishonesty (see, e.g., Gneezy, 2005, Sutter, 2009, Cappelen, Sorensen, and Tungodden, 2013), understanding how such acts arise and what economic environments attenuate or exacerbate their prevalence is an underexplored area of research. ${ }^{2}$ We begin with a simple model of dishonest acts that incorporates both moral cost and scrutiny as key features affecting whether or not an act is observed. The model yields testable predictions regarding the influence of various contextual features on dishonest behaviors.

We test our model with a field experiment in which parents of 3-6 year-old children have the possibility to increase their payoffs by misreporting the outcome of a private coin toss without being detected. Our model predicts that increased scrutiny results in less dishonesty - to

\footnotetext{
1 For example, recent estimates show that in the U.S., employees are responsible for as much as $\$ 994$ billion of annual losses due to occupational fraud (ACFE, 2008).

2 Interesting work by Hsee $(1995,1996)$ teaches us that people are not inherently honest or dishonest - rather, the level of honesty varies by context. For example, Hsee's work suggests that people cheat in some situations but not in others, and people vary with respect to the context in which they will choose to cheat.
} 
test this prediction, we vary whether the parent's child is in the room during the coin toss. Further, our model highlights that the moral cost associated with a dishonest act significantly impacts behavior. To evaluate the latter prediction empirically, we conduct two additional treatments in which we vary whether the payoff is a prize for the child or for the parent.

The effect of "scrutiny" on honesty may arise both because a parent does not want to look like a dishonest person in front of their child and, relatedly, because parents want to transmit positive attitudes towards honesty to their children. For this reason, our empirical examination of the scrutiny effect potentially provides insights into the origins of dishonesty. ${ }^{3}$ According to our model, parents may transmit honest behavior because acting dishonestly imposes a moral cost, which is strongest when the child is in the room. Moreover, our analysis enables us to discover empirically whether this scrutiny effect differs depending on whether the child is a son or a daughter.

Whether parents' impulse for dishonest behavior varies under the scrutiny of sons or daughters is an important empirical question. Several studies in economics and psychology have shown adult males to be more likely than females to engage in acts of dishonesty (Alm, Jackson and McKee, 2009; Jackson et al., 2002; Ward and Beck, 1990). For example, to study gender differences in the propensity to lie, Dreber and Johannesson (2008) used a sender and receiver game in which the sender has a monetary incentive to send a deceptive message. They found that men lie more than women (55\% vs. 38\%). This result accords well with Houser, Vetter and Winter (2012), who showed that men are more likely than women to incorrectly report the result of a private coin toss.

\footnotetext{
3 Relatedly, scholars have investigated the inter-generational transfer of skills, preferences and attitudes from parents to children. For example, Bisin and Verdier (2001) find paternalistic altruism to underlie parents' transmission of preferences and cultural values to children. Recent data suggest that parents also transmit risk and trust preferences to children (Dohmen et al., 2012).
} 
Field evidence also confirms that men cheat more than women. Data on fare dodging collected in Italy showed that men are more likely to cheat (Bucciol, Landini and Piovesan, 2013). Females were also found to be more likely to return excess change at the restaurant (Ofer, Shira and Bar-Eli, 2013) and had weaker cheating intentions on exams (Tibbetts, 1999). Tibbetts (1999) suggested that women have a stronger tendency to feel shame from actions that deviate from honesty. The paper also finds that men display less self-control, leading them to disobey rules more frequently. Fosgaard, Hansen and Piovesan (2013) manipulated the moral cost of dishonesty. They found that women are more honest than men in situations where the moral cost of dishonesty is higher (see also Friesena and Gangadharan, 2012; and Erat and Gneezy, 2012 for related results).

In line with the predictions of our model, we observe the highest level of cheating in the setting with low moral cost and no scrutiny: when the parent is alone and the prize is for the child. Overall, parents rarely cheat when their child is present. That is, the impulse to benefit one's child through dishonest acts is extinguished by that same child's scrutiny, perhaps due to the parent's desire to model honesty. At the same time, when parents are alone, they cheat more when the prize is for their child than when it is for themselves. Thus, the impulse to benefit one's child through dishonesty seems substantially greater than the impulse to benefit oneself in that same way. Finally, we find that parents act more dishonestly in front of sons than daughters. This finding has the potential of shedding light on the origins of the widely documented gender differences in cheating behavior among adults discussed above.

The remainder of our study is crafted as follows. Section 2 provides a simple theoretical framework and discusses related literature in light of the theory. Section 3 describes the experiment design and procedures. Section 4 summarizes findings. Section 5 concludes. 


\section{Background and Economic Model of Dishonesty}

\subsection{Related Literature}

Research on dishonesty, deception, lying and cheating spans many fields including psychology (e.g., Hegarty and Sims, 1978; Beck and Ajzen, 1991; Depauloet al., 1996; Monin and Jordan, 2009), neuroscience (e.g., Cazzaniga, 1995; Yang et al., 2005; Harvey et al., 2010) and philosophy (Green, 2004). Within economics, a growing body of literature has found experimental evidence of individual dishonesty when cheating is unobservable (Erat and Gneezy, 2012; Gneezy, 2005; Fischbacher and Föllmi-Heusi, 2013; Abeler et al., 2014; Freeman and Gelberg, 2010; Bucchiol and Piovesan, 2009; Pruckner and Sausgruber, 2008; Cappelen, Sorensen, and Tungodden, 2013; Houser et al., 2012; Hao and Houser, 2013) and in cheap talk games in the laboratory (Sutter, 2009; Charness and Dufwenberg, 2006 Gneezy, 2005; Chen and Houser, 2014). Studies also found that some individuals are inherently honest and are not tempted to engage in cheating behavior (Greene and Paxton, 2009), and some individuals cheat only a little, potentially due to the desire to preserve a favorable self-concept (Mazar et al., 2008).

The existing literature also confirms that context is extremely important in determining whether an individual will cheat. For example, Gneezy (2005) found that the consequences of the lie (relevant payoffs) turn out to have an important impact on behavior. Erat and Gneezy (2012) found that a non-negligible number of people lie when it benefits another (see also Gino et al., 2013; Gino and Pierce, 2010), a result explained by the fact that individuals view their unethical actions as morally acceptable when others may benefit. Houser et al. (2012) found that when subjects perceive being treated unfairly in one environment, they are more likely to cheat in a 
subsequent unrelated context. Also, people are more likely to be dishonest after having observed their peers acting dishonestly (Gino et al., 2009). In addition, Mazar et al. (2008) and Vohs and Schooler (2008) reported that dishonesty decreases after moral reminders.

Recent papers also reported that children ages 5-15 behave dishonestly when given the opportunity to do so (Bucciol and Piovesan, 2011) and that they are also willing to act unfairly if they can maintain an appearance of fairness in front of the experimenter (Shaw et at. 2014). Interestingly, Hays and Carver (2014) found that school-age children (but not preschoolers) were more likely to cheat if they had been previously deceived.

\subsection{Theoretical Framework}

We provide a simple theoretical framework that incorporates moral cost in an individual's decision to behave dishonestly. Our economic model of dishonesty closely follows that of Levitt and List (2007), and has a utility-maximizing individual $i$ making a single action $a$. The action has two channels to which it potentially affects utility: wealth (denoted by $W$ ) and a non-pecuniary moral cost or benefit (denoted as $M$ ). As the stakes increase (denoted as $v$ ), the more the action affects $W$. Likewise, actions that might be viewed as immoral or anti-social may impose economic costs (see Akerlof and Kranton, 2000; 2005; Gazzaninga, 2005).

As the negative impact on others increases, the moral $\operatorname{cost} M$ grows larger in absolute value. Individuals also pay a moral cost for violating social norms or legal rules that govern behavior. Following Levitt and List (2007), we denote such norms as $n$. Also, as Levitt and List (2007) note "moral concerns depend on the nature and extent of how an individual's actions are scrutinized-such as whether the act is in front of one's children." We denote the effect of scrutiny as $s$, leading to a utility function for individual $i$ as follows:

$$
U_{i_{-}}(a, v, n, s)=M_{i}(a, v, n, s)+W_{i}(a, v)
$$


In the context of our experimental design, described below, this framework highlights several relevant predictions. First, the parent will be less likely to act dishonestly when the child is present, both because the level of scrutiny $s$ is higher and also because of the higher moral cost associated with dishonesty when one's child is observing the act.

Parents play a central role in a child's socialization and moral development, especially at young ages (Cunha and Heckman, 2009; Maccoby, 1992). Related work on preference development predicts that parents will transmit preferences and cultural values to children due to paternalistic altruism (Bisin and Verdier, 2001). It may be more difficult for parents to rationalize dishonest behavior if their child is witnessing it, which would lead to lower rates of dishonesty (e.g., If I cheat in front of my child I will feel bad.). To the extent that parents may feel morally obligated to model honest behavior to children, choosing to behave dishonestly when a child is present imposes a higher moral cost.

The second comparative static relates to the recipient of the payoff from cheating. In our experiment, parents are randomized to either a treatment in which the payoff is a toy for the child or cash for the parent. To address the directional differences we expect, we combine our economic model with related literature on self-image. According to Mazar et al. (2008), people do not cheat all the time because they gain utility from a positive self-image and are sensitive to the consequences of a lie. The premise of the theory is that individuals prefer to maintain a positive self-image, but will cheat if they can do so without negatively updating their self-image (Gur and Sackeim, 1979). Similar to the findings of Gino et al. (2013), parents in our study may have a 'license to cheat' when they are alone and when their cheating can benefit another (in this case, their child). While stealing cash is hard to rationalize, stealing a toy for a child may be easier to rationalize (e.g., I decided to cheat because this is what parents do for their child.). In 
other words, the moral cost of cheating is lower when the prize is for the child than for the parent. This leads us to the second prediction of our model, which is that the level of dishonesty should be higher when the prize is for the child than for the parent, and when the child is not present.

\section{Experimental Design and Procedures}

The experiment was conducted at the Griffin Early Childhood Center (see Appendix A for more detail on the setting). A total of 152 parent-child pairs were recruited and participated in the experiment, with children ranging in age from 3 to 6 . Most parents in the study were mothers because they were the most likely to bring their child in for the experiment $(88 \%$ were mothers while $12 \%$ were fathers). Each parent-child pair participated only once. The field experiment was conducted in a classroom at the school, and the parent-child pair participated one-on-one with an experimenter (in the parlance of Harrison and List (2004), we conducted an artefactual field experiment). Participation required approximately 15 minutes. Instructions were viewed via a video on the experimenter's computer (see Appendix B for instructions). Because it was important that both the parent and the child comprehend the procedures, both the instructions and the record sheet were created so that they could be understood by both parents and their children. $^{4}$

The experiment proceeded as follows. While the experimenter was out of the room, parents flipped two coins each with a green and blue side, and reported the outcome of the coin toss on a record sheet. Reporting \{green, green\} resulted in a prize, whereas reporting any other outcome did not result in a prize. Participants flipped each coin only once. We did not invite

\footnotetext{
${ }^{4}$ For instance, the instruction format was interactive and included several comprehension questions. The authors have experience in designing these sorts of experiments for young children, and used their expertise when designing this experiment.
} 
participants to cheat, though we did clearly indicate that we would not observe the outcome of the coin toss. ${ }^{5}$

We conducted four treatments using a 2x2 design in which we systematically varied whether the child was in the room during the coin toss, and whether the reward was for the parent or for the child (see Table 1). Parent-child pairs were randomly selected into one of the four treatments. In all treatments, the child was in the room with the parent while the instructions were read. In treatments where the parent flipped the coin alone ( $\mathrm{Pa} \_\mathrm{P}$ and $\left.\mathrm{Pa} \_\mathrm{C}\right)$, the child was asked to leave the room with the experimenter during the coin toss; whereas in treatments where the parent flipped the coin with the child (PC_P and PC_C), the child was asked to remain in the room with the parent.

To assure that the child would pay attention to the outcome of the coin toss in PC_P and PC_C, we incorporated child involvement in a natural way by instructing the child to play a card matching game during the experiment. ${ }^{6}$ In treatments where the child left the room with the experimenter, the experimenter played the same coin toss and card matching game in the hall with the child - however, as in the other treatments, the parent and child were instructed that it is the adult's coin toss outcome that 'counted' for winning the prize.

\section{[ TABLE 1 ABOUT HERE ]}

Prizes were shown to the participants prior to the coin toss. In the treatment where the prize was for the parent ( $\mathrm{PC} \_\mathrm{P}$ and $\left.\mathrm{Pa} \_\mathrm{P}\right)$, the parent received $\$ 10$ wrapped with a bow if the reported outcome was \{green, green\} and nothing otherwise. In the treatment where the prize

\footnotetext{
${ }^{5}$ Related cheating experiments using dice or coins are reported by Fischbacher and Föllmi-Heusi (2013); Bucciol and Piovesan (2008), Houser et al. (2012) and Fosgaard et al. (2013).

${ }^{6}$ In the card matching game, the child was given 2 blue and 2 green cards. The child was told to watch for the outcome of the coin toss, and then hold up the cards corresponding to the outcome (e.g., 2 blue cards for both coins blue side up, and so on). Then the child was asked to put the cards away and wait for the experimenter to return in order to give the outcome sheet to him/her.
} 
was for the child ( $\mathrm{PC} \_\mathrm{C}$ and $\mathrm{Pa} \_\mathrm{C}$ ), the child could choose between several different genderneutral prize packs if the reported outcome was \{green, green\}, and nothing otherwise. The prize pack consisted of a 5" stuffed zoo animal toy (choice of bear, zebra, giraffe, or lion), a colorful pencil, and other small trinkets, so that the approximate price of each prize pack was also around $\$ 10$. At the end of the session, all parents also received the pre-announced $\$ 10$ show-up fee.

\section{Results}

Following other studies in this literature, we do not observe cheating directly. Instead, we compare the rate of reported wins to the expected rate to infer whether cheating occurred. ${ }^{7}$ While the objective probability of winning the prize is 0.25 , we find winning rates of 0.39 on average. A reported rate of winning that is different from the expected rate suggests that participants are providing dishonest reports for private benefit.

\subsection{Testing Model Predictions}

Consider the first prediction of our model, that the presence of the child decreases the likelihood of cheating. The rates of winning when a parent is alone are 0.46 , while rates when the parent's child is present are 0.33 (pooling the parent and child prize treatments, respectively). This suggests that parents cheat less in the presence of a child. The difference is marginally significant $\left(\mathrm{Chi}^{\wedge} 2 p\right.$-value $\left.=0.09\right)$ and conforms to the predictions of the model, as cheating rates should decline both due to decrease in scrutiny and due to decreases in the moral cost associated with cheating when one's child is not present. This brings us to our first result:

\footnotetext{
${ }^{7}$ Houser et al. (2012) show that observed outcome frequencies can be used to infer cheating rates in simple coinflip games under the assumption that subjects do not cheat to their disadvantage. Because estimated cheating rates and observed winning rates are monotonically related, our analysis here focuses exclusively on the latter.
} 
Result 1: The presence of the child decreases the likelihood that the parent will report a winning outcome (i.e., cheat).

We now turn to the next prediction, that cheating is greater when the reward is for the child than for the parent. The winning rates are 0.36 and 0.43 , when the prize is for the parent and child, respectively (pooling the child presence treatments). This $20 \%$ increase in win rates when the prize is for the child is consistent with the model's predictions. The difference, however, is not statistically significant $\left(\mathrm{Chi}^{\wedge} 2 p\right.$-value $\left.>0.10\right)$.

Next, we turn to exploring the underlying pattern of cheating rates in the $2 \times 2$ experiment. As reported in Table 2 and Figure 1, rates of winning are strongly influenced by context. Win rates of $0.29,0.38$ and 0.34 in treatments $\mathrm{PC}_{-} \mathrm{C}_{2} \mathrm{PC}_{-} \mathrm{P}$ and $\mathrm{Pa} \mathrm{P}_{-}$are all higher than 0.25 , though not significantly individually ( $\mathrm{Chi}^{\wedge} 2$ test $p$-values $>0.10$ for each treatment). When pooled, however, the differences are significant $(p$-value $=0.05)$.

\section{[ TABLE 2 ABOUT HERE ]}

\section{[ FIGURE 1 ABOUT HERE ]}

Our model predicts greatest cheating in $\mathrm{Pa} \_\mathrm{C}$ (parent alone and gift is for child), and this is in fact what we observe: in $\mathrm{Pa}-\mathrm{C}$, the winning rates are at 0.58 , while in the other three treatments winning rates are only 0.33 on average. $\mathrm{Pa}$ C $\mathrm{C}$ has statistically significantly higher winning rates than $\mathrm{Pa}_{-} \mathrm{P}\left(\mathrm{Chi}^{\wedge} 2 p\right.$-value $\left.=0.04\right)$ and than $\mathrm{PC}_{-} \mathrm{C}\left(\mathrm{Chi}^{\wedge} 2 p\right.$-value $\left.=0.01\right)$. Indeed, Pa_C also has significantly higher winning rates than $\mathrm{PC} \_\mathrm{P}\left(\mathrm{Chi}^{\wedge} 2 p\right.$-value $\left.=0.09\right)$. This is our second result: 
Result 2: The highest winning (cheating) rate is observed in the condition with lowest moral cost: when the parent is alone and the gift is for the child.

The Logit regression reported in Table 3 provides additional evidence for our results. Here, the dependent variable is reporting a win (=1 for win and 0 otherwise), dummies and interactions are included for the treatments, and we include fixed effects for research assistants

(8 different research assistants carried out the study one-on-one with the parent/child pair). Notice that we observe higher rates of cheating when the prize is for the child (coefficient of $0.84, p$-value $<0.10$ ). We also observe a significant, large negative interaction effect (coefficient of $-1.4, p$-value $<0.05)$ : the highest rate of cheating occurs when the gift is for the child and the parent is alone. The Child Present dummy is positive, but small and insignificant.

\section{[ TABLE 3 ABOUT HERE ]}

\subsection{Gender Differences}

Next, we turn to an investigation of gender differences. Recall that gender differences are observed among adults in related experiments, with men cheating more than women in most studies (Dreber and Johannesson, 2008; Friesena and Gangadharan, 2012; Ward and Beck, 1990). While our theory does not directly predict any differences in dishonesty by gender, our experiment allows us to answer questions about origins of dishonesty by considering whether sons or daughters receive differential treatment in the game.

Aggregating data for both prizes, Figure 2 provides an overview of the cheating rates when the child is a girl or a boy, according to whether the child is with the parent or not. While gender of the child does not matter when the parent is alone $\left(\mathrm{Chi}^{\wedge} 2 p\right.$-value $\left.>0.10\right)$, we do observe significant differences when the child is in the room. Specifically, as compared to when 
a son is in the room, in the presence of a daughter, parents are significantly less likely to report a winning outcome $\left(\mathrm{Chi}^{\wedge} 2 p\right.$-value $\left.=0.02\right)$. Specifically, the rate of reported wins when a daughter is with the parent is 0.28 (insignificantly different from expected win rate of 0.25 ), while the reported rate of wins under the scrutiny of a son is 0.42 (statistically significantly different from the expected win rate of 0.25 , t-test $p$-value $<0.01$ ). This is the final result:

Result 3: Parents are more willing to cheat in front of sons than daughters.

Result 3 could be explained by our theory if we assumed that the moral cost of cheating in front of daughters is higher than the moral cost of cheating in front of sons. Such an assumption would lead to the prediction that cheating rates are lower when daughters are present as compared to sons, yet cheating rates are similar for parents of daughters and sons when their child is absent. This assumption is plausible if we imagine that moral cost is tied to social norms - knowing that it is more important for girls to grow up honest, parents may incur a higher moral cost from lying in front of a girl.

\section{[ FIGURE 2 ABOUT HERE ]}

\subsection{Elasticity of Honesty}

Our economic model also provides a framework for investigating the price elasticity of honesty. Within $W$, there is a standard way of computing elasticity. Assuming that honesty is a normal good with all the standard features of private goods, our economic model suggests that as the price (pecuniary or non-pecuniary) of honesty increases, the quantity demanded for honesty decreases. The elasticity for honest behavior can therefore be calculated: that is, we can compute how responsive honest acts are to changes in $v$. For example, when using the results of Fischbacher and Follmi-Heusi (2013), a back of the envelope calculation yields price elasticities 
of -0.38 and -0.69 . In Gneezy (2005), two elasticities also emerge from the empirical results, 0.17 and $-0.33 .{ }^{8}$ These figures point to our conclusion that the demand for honesty is relatively inelastic. This is interesting because one could now conclude that the contextual estimates that we find, and the broader literature finds, show the importance of context in determining how honesty responds to price.

\section{Discussion \& Conclusion}

When humans are given the chance to behave dishonestly (e.g. they have the opportunity to cheat to their own advantage), Becker (1968) predicted their behavior would be determined by the costs and benefits of their actions. In fact, the decision to act dishonestly seems to be influenced by a much broader set of variables than these. Further, related literature suggests that individuals trade-off between the pecuniary value of dishonest acts and the moral and self-image costs that can result from cheating.

We proposed a model that incorporates moral costs and can shed light on the underlying channels through which context may influence decisions to behave dishonestly. The central prediction of our model is that a higher moral cost results in a lower rate of dishonesty. We tested the model using a field experiment with parent-child pairs to investigate the willingness of parents to lie about the outcome of a coin toss when 1) the child is present or absent and 2) when the benefit of the lie is to the parent or to the child.

\footnotetext{
${ }^{8}$ In Fischbacher and Follmi-Heusi (2013), subjects roll a die and then self-report the number. They are paid the number they report, unless they report six in which case they earn zero. Thus, if there are no costs to lying and people are earnings maximizers, everyone should report 5. The price of an honest report $\mathrm{X}$ is the difference between what they could have earned by lying (5) and their report $X$, unless $X=6$ in which case the price is 5 . Using the percent of subjects who received each payout (0-5), we computed quantity of each report as a function of price using Matlab's polyfit function for the first and second degree polynomial. Letting Qn be the $\mathrm{n}$ degree polynomial, we have: $\mathrm{Q} 1=-5.82 \mathrm{P}+31.23$ and $\mathrm{Q} 2=1.35^{\wedge} 2-12.59 \mathrm{P}+35.74$. To evaluate the elasticity, we assumed the weighted average (Pavg=1.48) and the corresponding quantities are $\mathrm{Q} 1=22.6$ and $\mathrm{Q} 2=20.06$. Thus, $\mathrm{E} 1=-0.38$ and $\mathrm{E} 2=-0.69$. In Gneezy (2005) one can calculate similarly, and discover elasticity values of -0.17 and -0.33 .
} 
Consistent with a broad literature, we find cheating rates are significantly affected by context. Specifically, our data points to three major conclusions. First, parents are significantly less likely to act dishonestly when the child is in the room, pointing to the importance of scrutiny and moral cost. Second, parents are least dishonest when the child is in the room and the payoff (gift) is a toy for the child rather than cash for the parent. Third, the child's gender matters: parents are significantly more likely to cheat in front of sons than daughters. Our results provide evidence for the importance of moral costs in settings where dishonesty is possible, and support our theory.

In addition to shedding light on the moral costs, our paper also provides some evidence on the transmission of honesty (and dishonesty) in society. The diminished impulse to lie in front of their own child suggests that parents may attempt to model honest behavior to children, thereby transmitting honesty. This result connects to the literature on inter-generational transfer of preferences, and provides micro-level evidence that parents invest in their child's noncognitive human capital. Thus, while some parents may choose to act dishonestly in private, they also seem aware of the benefits of modeling honest behavior to their children.

Our results may thus provide insights into the origins of dishonesty: gender differences in cheating rates among adults could be driven by differences in the way girls and boys are socialized by parents at early ages. This is consistent with the findings of Hayes and Carver (2014), who find that children who are exposed to lying adults are also more likely to lie. Combining this with the findings of our paper, one might speculate that adult males are found to lie more often than adult females because, in part, parents constrain their lying behavior to a greater degree under the scrutiny of daughters than sons. In addition, given the differences in 
dishonesty our participants have observed among adults in their daily lives, it is possible that they feel more morally obligated to be honest in front of daughters than in front of sons.

Finally, this research also contributes to our general understanding of how cheating to help another may differ from cheating to help oneself. In line with Gino et al. (2013), when their child was not present the parents in our study were more likely to lie to benefit their child than to benefit themselves. Indeed, a recent paper that investigates the transmission of lying behavior among socially connected individuals finds that an individual's lying tendencies can be predicted by the lying tendencies of his or her friends and family members (Mann et al., 2014). 


\section{References}

Abeler, Johannes, Anke Becker, and Armin Falk. "Representative Evidence on Lying Costs." Journal of Public Economics, 2014. doi:10.1016/j.jpubeco.2014.01.005.

Akerlof, George A., and Rachel E. Kranton. "Economics and Identity." Quarterly Journal of Economics 115, no. 3 (2000): 715-53. doi:10.1162/003355300554881.

Akerlof, George A., and Rachel E. Kranton. "Identity and the Economics of Organizations." Journal of Economic Perspectives 19, no. 1 (2005): 9-32. doi:10.1257/0895330053147930.

Alm, James, Betty R. Jackson, and Michael Mckee. "Getting the Word Out: Enforcement Information Dissemination and Compliance Behavior." Journal of Public Economics 93, no. 3-4 (2009): 392-402. doi:10.1016/j.jpubeco.2008.10.007.

Ariely, Dan. The (Honest) Truth About Dishonesty: How We Lie to Everyone-- Especially Ourselves. UK: HarperCollins, 2012.

Azar, Ofer H., Shira Yosef, and Michael Bar-Eli. "Do Customers Return Excessive Change in a Restaurant?" Journal of Economic Behavior \& Organization 93 (2013): 219-26. doi:10.1016/j.jebo.2013.03.031.

Beck, Lisa, and Icek Ajzen. "Predicting Dishonest Actions Using the Theory of Planned Behavior." Journal of Research in Personality 25, no. 3 (1991): 285-301. doi:10.1016/0092-6566(91)90021-H.

Becker, Gary S. "Crime and Punishment: An Economic Approach." Journal of Political Economy 76, no. 2 (1968): 169. doi:10.1086/259394.

Bisin, Alberto, and Thierry Verdier. "The Economics of Cultural Transmission and the Dynamics of Preferences." Journal of Economic Theory 97, no. 2 (2001): 298-319. doi:10.1006/jeth.2000.2678. 
Bucciol, Alessandro, and Marco Piovesan. "Luck or Cheating? A Field Experiment on Honesty with Children." Journal of Economic Psychology32, no. 1 (2011): 73-78. doi:10.1016/j.joep.2010.12.001.

Bucciol, Alessandro, Fabio Landini, and Marco Piovesan. "Unethical Behavior in the Field: Demographic Characteristics and Beliefs of the Cheater." Journal of Economic Behavior \& Organization 93 (2013): 248-57. doi:10.1016/j.jebo.2013.03.018.

Cappelen, Alexander W., Erik Ø. Sørensen, and Bertil Tungodden. "When Do We Lie?" Journal of Economic Behavior \& Organization $93 \quad$ (2013): 258-65. doi:10.1016/j.jebo.2013.03.037.

Cazzaniga, Michael S. "Consciousness and the Cerebral Hemispheres." In The Cognitive Neurosciences. Mit Press, 1995.

Charness, Gary, and Martin Dufwenberg. "Promises and Partnership." Econometrica 74, no. 6 (2006): 1579-601. doi:10.1111/j.1468-0262.2006.00719.x.

Chen, Jingnan, and Daniel Houser. "Promises and Lies: An Experiment on Detecting Deception." ICES Working Paper, No 1038, 2013.

Cunha, Flavio, and James J. Heckman. "Investing in Our Young People." Rivista Internazionale Di Scienze Sociali 117, no. 3 (2009): 387-418. doi:10.3386/w16201.

Depaulo, Bella M., Deborah A. Kashy, Susan E. Kirkendol, Melissa M. Wyer, and Jennifer A. Epstein. "Lying in Everyday Life." Journal of Personality and Social Psychology 70, no. 5 (1996): 979-95. doi:10.1037//0022-3514.70.5.979.

Dreber, Anna, and Magnus Johannesson. "Gender Differences in Deception." Economics Letters 99, no. 1 (2008): 197-99. doi:10.1016/j.econlet.2007.06.027.

Erat, Sanjiv, and Uri Gneezy. "White Lies." Management Science 58, no. 4 (2012): 723-33. doi:10.1287/mnsc.1110.1449.

Fischbacher, Urs, and Franziska Föllmi-Heusi. "Lies In Disguise-An Experimental Study On Cheating." Journal of the European Economic Association 11, no. 3 (2013): 525-47. doi:10.1111/jeea.12014. 
Fosgaard, Toke Reinholt, Lars Gaarn Hansen, and Marco Piovesan. "Separating Will from Grace: An Experiment on Conformity and Awareness in Cheating." Journal of Economic Behavior \& Organization 93 (2013): 279-84. doi:10.1016/j.jebo.2013.03.027.

Friesen, Lana, and Lata Gangadharan. "Individual Level Evidence of Dishonesty and the Gender Effect." Economics Letters 117, no. 3 (2012): 624-26. doi:10.1016/j.econlet.2012.08.005.

Gino, Francesca, and Lamar Pierce. "Dishonesty in the Name of Equity." Psychological Science 20, no. 9 (2009): 1153-160. doi:10.1111/j.1467-9280.2009.02421.x.

Gino, Francesca, and Lamar Pierce. "Lying to Level the Playing Field: Why People May Dishonestly Help or Hurt Others to Create Equity." Journal of Business Ethics 95, no. S1 (2010): 89-103. doi:10.1007/s10551-011-0792-2.

Gino, Francesca, Erin L. Krupka, and Roberto A. Weber. "License to Cheat: Voluntary Regulation and Ethical Behavior." Management Science 59, no. 10 (2013): 2187-203. doi:10.1287/mnsc.1120.1699.

Gino, Francesca, Shahar Ayal, and Dan Ariely. "Self-serving Altruism? The Lure of Unethical Actions That Benefit Others." Journal of Economic Behavior \& Organization 93 (2013): 285-92. doi:10.1016/j.jebo.2013.04.005.

Gneezy, Uri. "Deception: The Role of Consequences." American Economic Review 95, no. 1 (2005): 384-94. doi:10.1257/0002828053828662.

Green, Stuart P. "Cheating." Law and Philosophy 23, no. 2 (March 2004): 137-85. http://www.jstor.org/stable/4150568.

Greene, J. D., and J. M. Paxton. "Patterns of Neural Activity Associated with Honest and Dishonest Moral Decisions." Proceedings of the National Academy of Sciences 106, no. 30 (2009): 12506-2511. doi:10.1073/pnas.0900152106.

Gur, Ruben C., and Harold A. Sackeim. "Self-deception: A Concept in Search of a Phenomenon." Journal of Personality and Social Psychology 37, no. 2 (1979): 147-69. doi:10.1037//0022-3514.37.2.147. 
Hao, Li, and Daniel Houser. "Perceptions, Intentions, and Cheating." ICES Working Paper, No 1039, 2013.

Harrison, Glenn W., and John A. List. "Field Experiments." Journal of Economic Literature 42, no. 4 (2004): 1009-055. doi:10.1257/0022051043004577.

Harvey, Ann H., Ulrich Kirk, and George H. Denfield. "Monetary Favors and Their Influence on Neural Responses and Revealed Preferences." The Journal of Neuroscience 30, no. 28 (July 14, 2010): 9597-602. doi:http://dx.doi.org/10.1523/JNEUROSCI.1086-10.2010.

Hays, Chelsea, and Leslie J. Carver. "Follow the Liar: The Effects of Adult Lies on Children's Honesty." Developmental Science 17, no. 6 (2014): 977-83. doi:10.1111/desc.12171.

Hegarty, W. Harvey, and Henry P. Sims. "Some Determinants of Unethical Decision Behavior: An Experiment." Journal of Applied Psychology63, no. 4 (1978): 451-57. doi:10.1037//0021-9010.63.4.451.

Houser, Daniel, Stefan Vetter, and Joachim Winter. "Fairness and Cheating." European Economic Review 56, no. 8 (2012): 1645-655. doi:10.1016/j.euroecorev.2012.08.001.

Jackson, Chris J., Stephen Z. Levine, Adrian Furnham, and Nicole Burr. "Predictors of Cheating Behavior at a University: A Lesson From the Psychology of Work." Journal of Applied Social Psychology 32, no. 5 (2002): 1031-046. doi:10.1111/j.1559-1816.2002.tb00254.x.

Jordan, Alexander H. "The Dynamic Moral Self: A Social Psychological Perspective." In Moral Self, Identity and Character: Prospects for a New Field of Study, by Benoît Monin. Cambridge University Press, 2009.

Levitt, Stevin D., and John A. List. "What Do Laboratory Experiments Measuring Social Preferences Reveal About the Real World." Journal of Economic Perspectives 21, no. 2 (2007): 157-74. doi:10.1257/jep.21.2.153.

Maccoby, Eleanor E. "The Role of Parents in the Socialization of Children: An Historical Overview." Developmental Psychology 28, no. 6 (1992): 1006-017. doi:10.1037/00121649.28.6.1006. 
Mann, Heather, Ximena Garcia-Rada, Daniel Houser, and Dan Ariely. "Everybody Else Is Doing It; Exploring Social Transmission of Lying Behavior." Working Paper, 2014. doi:10.1371/journal.pone.0109591.

Mazar, Nina, On Amir, and Dan Ariely. "The Dishonesty of Honest People: A Theory of SelfConcept Maintenance." Journal of Marketing Research 45, no. 6 (2008): 633-44. doi:10.1509/jmkr.45.6.633.

Shaw, Alex, Natalia Montinari, Marco Piovesan, Kristina R. Olson, Francesca Gino, and Michael I. Norton. "Children Develop a Veil of Fairness." Journal of Experimental Psychology: General143, no. 1 (2014): 363-75. doi:10.1037/a0031247.

Sutter, Matthias. "Deception Through Telling the Truth?! Experimental Evidence From Individuals and Teams*." The Economic Journal 119, no. 534 (2009): 47-60. doi:10.1111/j.1468-0297.2008.02205.x.

Tibbetts, Stephen G. "Differences between Women and Men regarding Decisions to Commit Test Cheating." Research in Higher Education 40, no. 3 (June 1999): 323-42.

Uddin, Lucina Q., Jan Rayman, and Eran Zaidel. "Split-brain Reveals Separate but Equal Selfrecognition in the Two Cerebral Hemispheres." Consciousness and Cognition 14, no. 3 (2005): 633-40. doi:10.1016/j.concog.2005.01.008.

Vohs, Kathleen D., and Jonathan W. Schooler. "The Value of Believing in Free Will: Encouraging a Belief in Determinism Increases Cheating." Psychological Science 19, no. 1 (2008): 49-54. doi:10.1111/j.1467-9280.2008.02045.x.

Ward, David A., and Wendy L. Beck. "Gender and Dishonesty." The Journal of Social Psychology 130, no. 3 (1990): 333-39. doi:10.1080/00224545.1990.9924589.

Yang, Y. "Prefrontal White Matter in Pathological Liars." The British Journal of Psychiatry 187, no. 4 (2005): 320-25. doi:10.1192/bjp.187.4.320. 
Table 1: Summary of Treatments

\begin{tabular}{l|cc}
\hline & Parent \& Child Together & Parent Alone (Child out of the room) \\
\hline Prize for Parent & $\begin{array}{c}\text { PC_P - 34 parent-child pairs } \\
\text { (28 mother and 6 father pairs) }\end{array}$ & $\begin{array}{c}\text { Pa_P - 38 parent-child pairs } \\
\text { (36 mother and 2 father pairs) }\end{array}$ \\
Prize for Child & $\begin{array}{l}\text { PC_C - 42 parent-child pairs } \\
\text { (35 mother and 7 father pairs) }\end{array}$ & $\begin{array}{c}\text { Pa_C - 38 parent-child pairs } \\
\text { (35 mother and 3 father pairs) }\end{array}$ \\
\hline
\end{tabular}

Table 2: Winning Rates by Treatment

\begin{tabular}{c|cc}
\hline Treatment & Frequency & Rate of Reported Wins \\
\hline PC_C & 42 & 0.286 \\
PC_P & 34 & 0.382 \\
Pa_C & 38 & 0.579 \\
Pa_P & 38 & 0.342 \\
\hline
\end{tabular}

Note: The probability of winning is $25 \%$ in all treatments.

Table 3: Predictive Regressions of Winning

\begin{tabular}{cc}
\hline & $(1)$ \\
& Reported Win \\
\hline Child Present Dummy & 0.150 \\
& $(0.497)$ \\
Gift for Child Dummy & $0.844^{*}$ \\
& $(0.476)$ \\
Interaction & $-1.401^{* *}$ \\
& $(0.689)$ \\
Observations & 152 \\
Number of assessors & 8 \\
\hline
\end{tabular}

Note: Standard errors in parentheses. Since 8 different research assistants carried out the study, this regression uses research assistant fixed effects. ${ }^{* * *} \mathrm{p}<0.01, * * \mathrm{p}<0.05, * \mathrm{p}<0.1$ 
Figure 1: Reported Rates of Winning by Treatment

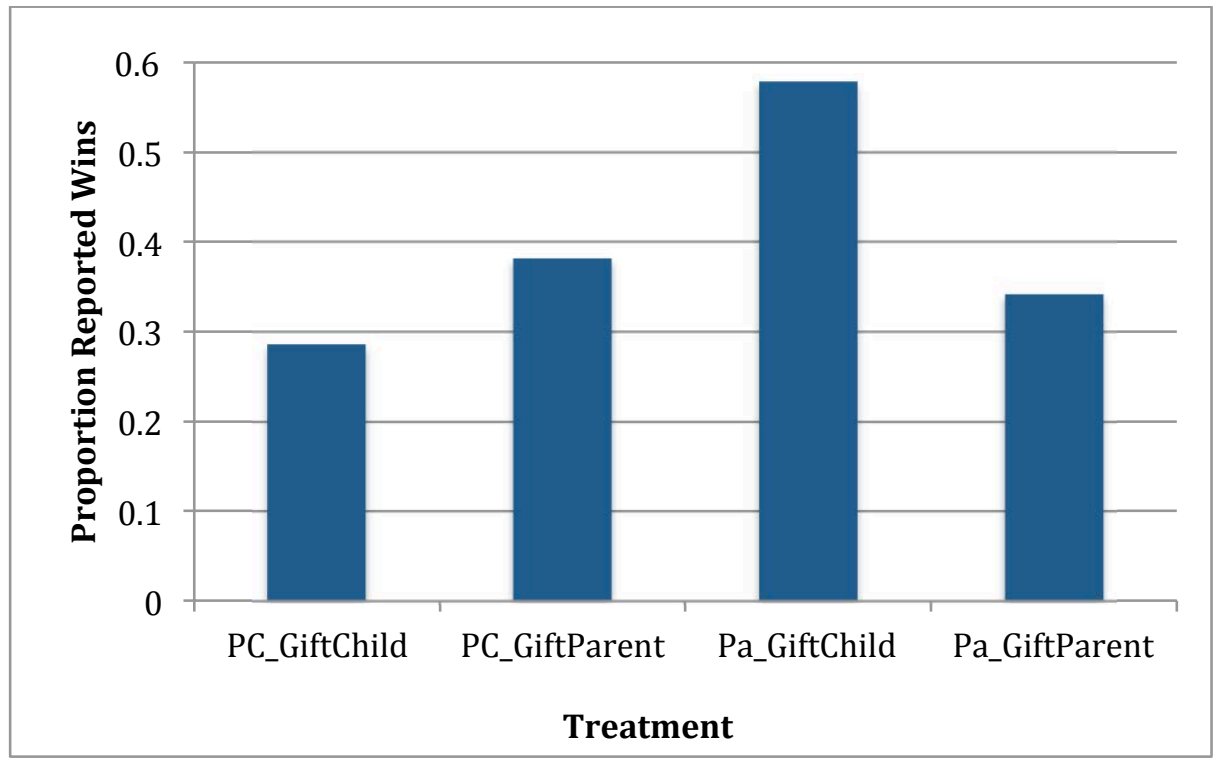

Figure 2: Rates of Winning by Gender of the Child

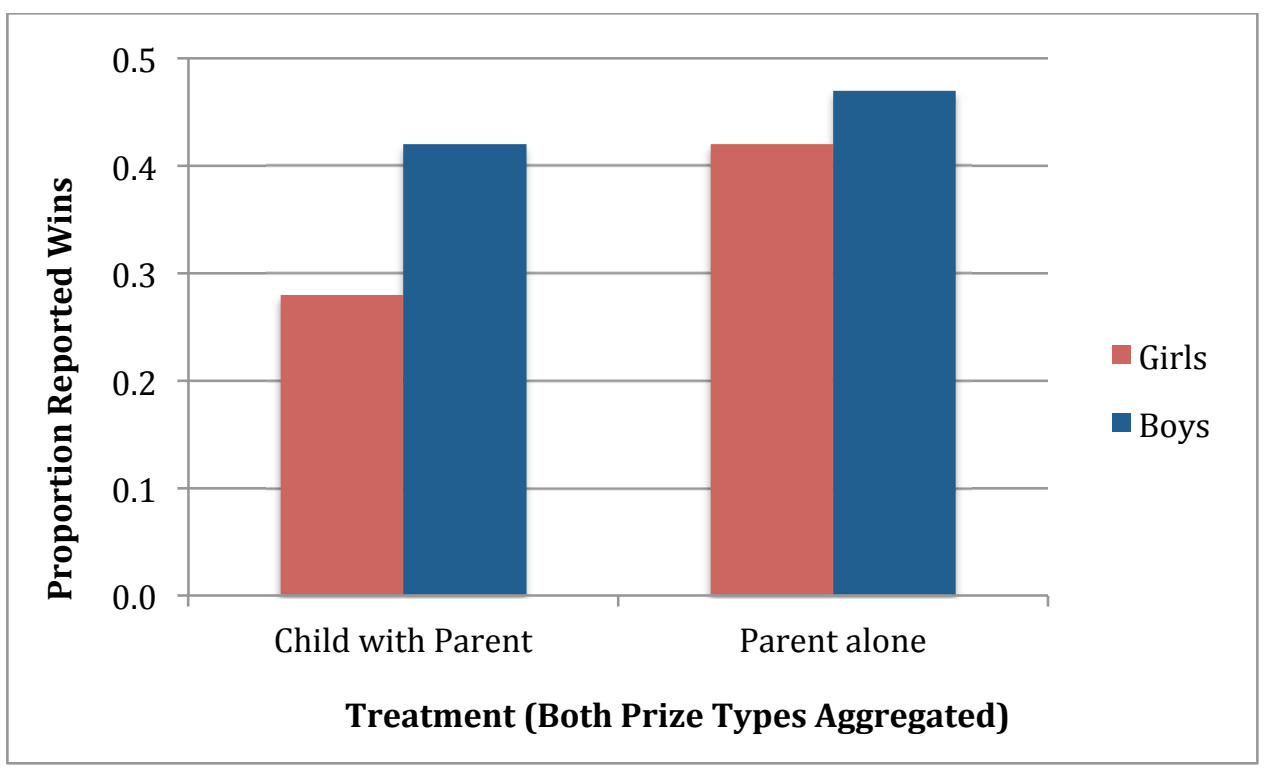

Note: 77 of the children are male and 75 of the children are female, split equally between the two categories (child with parent, and parent alone). 


\section{APPENDICES FOR WEB ONLY}

\section{Appendix A: Description of Study Environment}

\section{A.1. Griffin Early Childhood Center (GECC) Laboratory}

The studies were conducted at the Griffin Early Childhood Center (GECC) on July 26 and 27 in 2011 (Highland Campus Preschool). The GECC program was launched in August, 2010 and serves as a 'laboratory' for experiments of this sort. The GECC itself is a randomized field experiment testing the effects of different early childhood intervention programs for 3-5 year old children. Families from the 2010-11 and 2011-12 GECC cohorts were invited to participate in this incentivized "parent-child activity." When participants are recruited into GECC, the optional activities that are part of the program are explained. Participants did not know what the activity was about when they signed up. Parents were told that they would receive $\$ 10$ just for coming, and have the chance to earn more prizes, for a "Coin Toss Activity" that would take around 15-20 minutes of their time. Some parents and children had previously participated in activities that are unrelated to this project.

At GECC, a standardized system is in place for recruitment. Each prospective participant receives a flyer describing the length of the study, who can participate, and the show up fee. Each participant then receives up to 2 emails asking if he/she would like to set up an appointment. The day before the appointment, the parent receives a reminder call and at that time can change the appointment time. Parents who do not show up receive a call asking if they would like to reschedule (if slots are available only).

\section{A. 2. Environment Setup}

We followed a standard procedure developed at GECC to conduct the study. Most experiments involving children at GECC are conducted one-on-one with the experimenter - in this case, the parent-child pair participated in the experiment with one experimenter assigned to each pair. Thus, in a sense there were 152 separate sessions of the experiment. One of the authors was in charge of implementing the study, including training staff, monitoring recruitment, observing the staff during the duration of the experiment, and monitoring data entry. We used 8

\footnotetext{
${ }^{9}$ Note that the GECC was renamed to CHECC (Chicago Heights Early Childhood Center) in 2012, and is now known by the new name.
} 
different experimenters, who were all Research Assistants or full time staff at the University of Chicago working for the author and have experience in conducting other experiments at GECC. 5 of the experimenters were male, and 3 of the experimenters were female. 2 of the experimenters were fluent in Spanish, and conducted the experiment in Spanish for the Spanishspeaking parent-child pairs. The remaining experimenters conducted the experiment in English. The study also required the use of several waiting area assistants and babysitters, and check-in staff, who were also Research Assistants at the university or interns at the GECC.

\section{A.3. Procedure}

The parent/child pairs arrived at their appointment time to the sign-in desk, and were escorted to the waiting area, which had drawing activities available for children. Parent-child pairs who arrived with multiple parents (or multiple children) were asked to select which childparent pair will participate in the study. We recorded whether the mother or father participated as the parent. We do have some cases where two parents came with two children, in which case we have observations for 2 separate parent-child pairs within one family unit.

After the child felt comfortable in the environment, a waiting area assistant confirmed language preference and escorted the child to the next available experimenter. The waiting area assistant asked, "Are you ready to do the activity? I'm going to introduce you to my friend, do you want to come with me?" No child refused to do the activity. The matching of parent-child pairs to experimenter was random, since experimenters did not choose the pair and we were careful to instruct the waiting area assistant to bring the pair to the next available experimenter of the appropriate language.

Experimenters were given a schedule at the beginning of Day 1 that determined the random order in which they were to conduct the treatments. Different experimenters had different schedules in order to assure that different treatments were conducted on different times of the day. The callers who scheduled participants to session slots were not aware of the treatment schedule, and waiting room assistants were not aware of which experimenter was conducting which treatment at any one time, so assignment to treatment was also random.

Each experimenter had his/her own station, and experimenters were randomly assigned to stations on Day 1 and switched on Day 2. The Highland Campus Preschool consists of 5 large classrooms and two smaller experimentation rooms. For this experiment, 2 separate stations were 
created in each of 4 classroom using desks and room dividers to assure privacy, and 1 station was created in one of the smaller rooms, for a total of 13 stations.

Experiment instructions are available below. For consistency across experimenters, we employed a semi-automated procedure. The experimenter sat across from a laptop screen and next to the parent-child pair. Prior to the experimental sessions, we recorded the instructions in a video format, in which the experimenter acted as the "Activity Leader," while the character on the screen (played by one of the authors for the English version and a translator in the Spanish version) in the video explained the instructions to the parent-child pair out loud. The character on the screen was female in both the English and Spanish translation. No written instructions were distributed to parents. The instructions were interactive to assure understanding, involving stopping points in which the video character asked the child to repeat back an answer (.e.g., "What happens if both coins land green side up?). At these points, the Activity Leader stopped the video and asked the child to tell him/her the answer. Correction was done as needed, and parents were allowed to have their questions answered about the instructions at the end of the video demonstration (but not about the purpose of the experiment).

At one point during the video, the Activity Leader also displayed the appropriate prize incentive to subjects - several prizes were arranged in a clear box. The instructions also included a demonstration of the correct way to toss the coin, which was demonstrated both on-screen by the video character and in person by the Activity Leader. Finally, the parent was also asked to try a practice coin toss. ${ }^{10}$

After the instructions were read, the experimenter left the room (with or without the child, depending on treatment). The parent was instructed to flip the coin, record the outcome on the outcome sheet, and call for the experimenter when finished. The experimenter returned to the room either after approximately 5 minutes or after the parent came to the door to call for the experimenter. The experimenter checked to see if the parent-child pair won a prize, and if so, gave the prize to the parent-child pair. Then the experimenter gave the parent a short questionnaire to fill out in the waiting area at the completion of the study.

After the parent completed the questionnaire, the family proceeded to the check-out desk to receive the $\$ 10$ show up fee and sign out, and then left. Each child also received a small

\footnotetext{
10 The practice toss was conducted because during the pilot, parents complained about not knowing the "right" way to toss the coin. Thus, we devised a simple way to toss the coin that all parents were asked to follow.
} 
"show up fee" regardless of the outcome of the coin toss, and was allowed to pick out one or two small items from a clear box containing stickers, small candies, and erasers. The child was told about the show up fee at the beginning of the experiment instructions - "at the end of the game you will get some stickers for playing the game, ok? So pay attention to the rules!"

The parent-child pairs who completed the study generally did not interact with the parentchild pairs who had just arrived, primarily because the parents who had just completed the experiment were completing the surveys and getting ready to check out so that they could receive the $\$ 10$ show up fee, and the new arrivals were promptly getting assigned to an experiment station and leaving the waiting area. We did have assistants in the waiting area at all times, and we never noted any discussion of the experiment design or outcome.

\section{Appendix B: Experiment Instructions (Child Prize, Parent and Child Together - PC_C)}

\section{STAGE 1: GREETING}

Hello! I'm Miss Anya! And this is Mr. Teddy Bear! Nice to meet you! in Spanish: Hola, me llamo Jennie!

First of all, thanks for playing with us today. Teddy and I are going to help your Activity Leader today. I'm going to be talking to the kid in the room, so if I say YOU that means YOU, and if I say your parent, that means your mom or dad, okay?

[To child] At the end of the game, you will get some stickers and a candy for playing the game. Okay? So pay attention to the rules!

Also, today there will be the chance to win an extra prize.

\section{STAGE 2: GAME}

[To parent] Here is the sheet that your parent will take notes on for the game. In this game, you are going to toss two coins to find out whether you will win a prize.

We will use two coins like this, with a blue and a green face (show coins) Leader, can you show the coins? 
Both of you have a different job to do. Please only do the job that we ask you, okay?

[To Parent] Your parent is going to toss both of the coins. Then your parent is going to record the outcome on the sheet. Leader, can you show on the sheet while I talk about it? YOU get a prize if both coins land on GREEN, but you do NOT get a prize if each coin lands on a different color or if both coins land on BLUE. That means if both coins land GREEN side up, you will get a prize. But, if both coins land BLUE side up, you will not get a prize. And, if one coin lands BLUE side up but the other coin lands GREEN side up, you will not get a prize. When the coin toss is done, your parent is going to record the outcome on the recording sheet.

[To Child] Your job is going to be to match some cards to the side the coin lands on. You get 4 cards - two BLUE and two GREEN. Leader, can you show the cards? Great. Hold on to them. When your mom/dad tosses the coins, see whether they landed BLUE or GREEN up. Then put the two cards that match the coin toss on the table. If both coins land BLUE side up, you put up both BLUE cards. Leader, can you show that? If both coins land GREEN side up, you put up both GREEN cards. Leader, can you show that? But if one coin lands BLUE side up and the other coin lands GREEN side up, you put up a green card and a blue card. Leader, can you show that? Your second job will be to hand the sheet your mom/dad filled out back to me. Leader, can you show the sheet again?

\section{Question Set 1}

Now, do you remember whose job it is to toss the coins? [Parent's job]

Do you remember whose job it is to match the cards? [child's job]

Will you stay with your parent or go with the leader for the next part? [Stay]

Whose job is it to hand the outcome sheet back to me? [Child's job]

\section{STAGE 3: THE OUTCOME}

Now let's talk about how to record the outcome. On this sheet, your parent is going to circle what happened. GREEN means that both coins landed on GREEN and then you [child] get a prize. BLUE means that both coins landed on BLUE, and DIFFERENT means each coin landed 
on a different color and then you [child] do not get a prize.

Let's see an example. If the Leader tossed the coins and got TWO GREEN, the Leader will circle this outcome [GREEN]. Leader, please show what you would circle! Then, we know that the Leader will get a prize. But if the Leader tossed the two coins and got ONE BLUE and ONE GREEN, the Leader will circle this outcome. Then, we know that the Leader will not get a prize. Leader, please show what you would circle! [Demonstrate on a laminated sample sheet].

\section{Question Set 2}

[To child] Now, if your mom/dad tossed two coins and got TWO BLUE, can you point to the outcome that he/she would circle? [ask child to point. That's right, or No, its this one. And this means there would not be a prize]

[To Child] Now, if I tossed two coins and got one blue and one green, which cards are you going to put on the table? [That's right, this card and this card. / No, you put this card and this card.]

Now, remember - if both coins land on GREEN, do you get a prize or not? [Yes, that's right, you get a prize / or No, if both coins are GREEN color, that means you will not get a prize.

But if both coins land on BLUE, do you get a prize or not? [That's right, you don't get a prize /or No, you don't get a prize, you only get a prize if they both land GREEN side up.]

But if one coin lands on BLUE, and one coin lands on GREEN, do you get a prize or not? [That's right, you don't get a prize /or No, you don't get a prize, you only get a prize if they both land GREEN side up.]

\section{STAGE 4: PRIZES}

Now let's see the prizes you can get. 
Leader, please show the prizes! If you win the game, you can pick from one of these prizes [show a bin of several different toys].

But remember, no matter what is the outcome, you will get stickers and a candy for doing a good job in the game.

\section{STAGE 5: PLAYING THE GAME}

Now the Leader is going to show your parent how to flip the coin and then the leader will leave the room. Please flip the coin the way the leader showed you, it is the easiest way. And only flip each coin one time. Hold the coin in your palm like this, and then toss it up in the air, like this and let it land on the table.

Go ahead and give it a try. (Great, you flipped it correctly/ or No, please flip it like this and try again). Leader, did they do it correctly?

How many times should your parent flip each coin? (That's right, you should only flip each coin one time / or You should flip each coin just one time, okay?)

Nobody except you and your parent will see the outcome of the coin toss. After your parent is done doing the coin toss and recording the outcome, your parent should go ahead and put the coins and cards back in this bin. Then your parent should give you the outcome sheet to show the leader. After the Leader gets back, the Leader will ask you to give back the outcome sheet and will look on the outcome sheet to see if you won a prize or not.

\section{Question Set 3}

Do you remember, who will see the outcome of the coin toss? [That's right, only you will see the outcome. I won't see the outcome. / or, No, I won't see the outcome, only you will see the outcome] 
You will have 5 minutes to play the game. The leader will leave the room. If you finish early, just buzz the buzzer and the leader will come back!

Great, see you soon!

\section{STAGE 7: RESULTS}

Hello, I am back. [You won a prize/ or You didn't win a prize]. Can you please fill out this short questionnaire before you leave? Thank you for playing the game. 
PID:

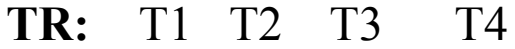

Date:

Time:

Activity Leader:

Outcome Sheet - Coin Toss Activity

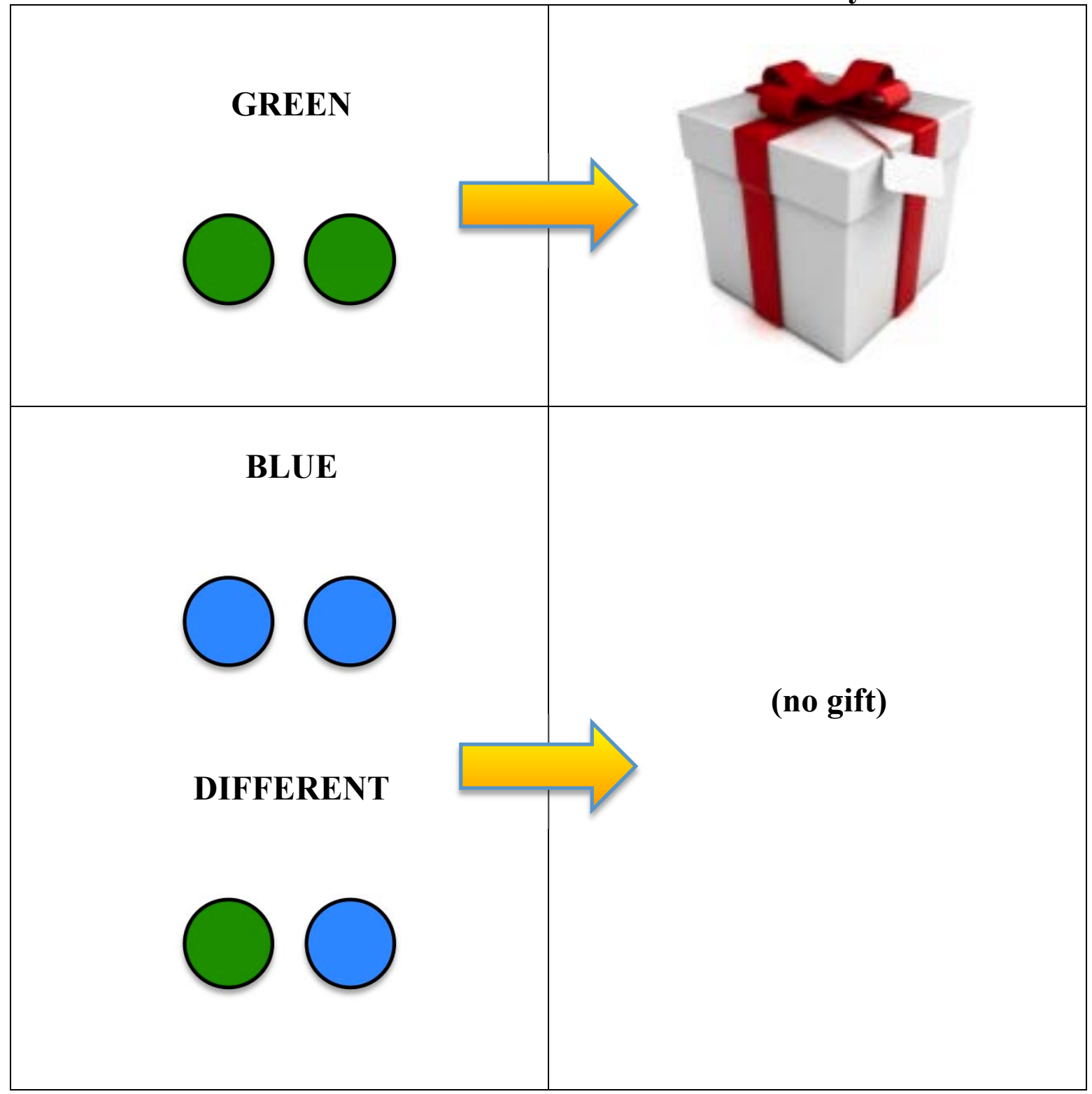

Child will hand outcome sheet to the activity leader!

1. Did you child do the card task right?

a. Yes, without my help

b. Yes, but she needed my help

c. She did not do the card task 